\title{
EXILIO CHILENO Y MIGRACIÓN INTERNA EN BARILOCHE. NOTAS SOBRE LA ORGANIZACIÓN DE LAS BARRIADAS POPULARES HACIA LOS AÑOS 80. ARGENTINA*
}

\author{
CHILEAN EXILE AND INTERNAL MIGRATION IN BARILOCHE. NOTES ON THE \\ ORGANIZATION OF THE POPULAR NEIGHBORHOODS TOWARDS THE '8OS. \\ ARGENTINA
}

José Daniel Benclowicz**

\begin{abstract}
El presente artículo se propone aportar al estudio de los procesos de migración y conformación de los barrios populares de San Carlos de Bariloche atendiendo al papel que jugaron los migrantes internos y chilenos. Para eso, me centro en un caso emblemático: el de los primeros vecinos del asentamiento 10 de Diciembre, que protagonizaron un importante proceso organizativo en el que activistas de origen chileno jugaron un papel central.
\end{abstract}

Palabras claves: Bariloche, activismo chileno, migración interna, organización de los barrios populares.

This paper aims to contribute to the study of migration and conformation processes of the popular neighborhoods of San Carlos de Bariloche, attending to the role played by internal and Chilean migrants. For that, I focus on an emblematic case: the first residents of the settlement 10 de Diciembre, which staged a significant organizational process in which activists of Chilean origin played a central role.

Key words: Bariloche, Chilean activism, internal migration, organization of popular neighborhoods.

\section{Introducción}

Desde principios del siglo XX, cuando las localidades patagónicas más populosas de la Argentina actual apenas contaban con unos centenares de habitantes, los inmigrantes chilenos resultaron clave para el desarrollo de la región, aportando buena parte de la fuerza de trabajo que requirieron los variados emprendimientos desplegados a lo largo del siglo. La ciudad de San Carlos de Bariloche es un buen ejemplo de esta dinámica. La bajísima densidad poblacional de la región en general y de Bariloche en particular, fue compensada con la afluencia de trabajadores chilenos. Junto con ellos, los migrantes internos provenientes de las áreas rurales circundantes, más numerosos aún que los anteriores durante las últimas décadas, conformaron el núcleo asalariado que permitió el desarrollo capitalista de la zona y el desarrollo urbano (Benclowicz 2012a).

La conjunción de los procesos migratorios interno y chileno dieron lugar a la conformación de las barriadas populares de Bariloche, caracterizadas por la precariedad de las viviendas y la falta de infraestructura, agravadas por la severidad del clima patagónico. Es en este punto en el que se introduce el presente trabajo, que pretende aportar al conocimiento de los procesos migratorios, las representaciones y las prácticas de los sectores populares de Bariloche, una línea de investigación que se viene desarrollando crecientemente. En efecto, durante los últimos años, distintos autores han abordado aspectos variados de estos temas. Kropff, (2002 y 2005), Fuentes y Núñez (2007 y 2008); Barelli (2014) Benclowicz (2012a y 2012b), entre otros, han indagado en torno de las experiencias populares en general y de los inmigrantes chilenos en particular, y advertido acerca de la puesta en circulación de informaciones e imágenes que presentan a Bariloche como "la Suiza" argentina, que ignoran esas experiencias. A su vez, se abordó la cuestión de las dificultades para el acceso a la tierra (Caram 2009, Benclowicz 2012a y 2012b) y se ha identificado el desarrollo de patrones sociogeográficos de asentamientos, que refuerzan las carencias de amplios sectores (Matossian 2009 y 2010).

Entre las décadas de 1970 y 1980 en particular, Bariloche experimentó un acelerado incremento

\footnotetext{
* Resultado Proyecto PICTO 2010-0184.

** Instituto de Investigaciones en Diversidad Cultural y Procesos de Cambio (IIDyPCa), Consejo Nacional de Investigaciones Científicas y Técnicas (CONICET) / Universidad Nacional de Río Negro (UNRN). Río Negro, Argentina. Correo electrónico: jd.benclowicz@gmail.com
} 
demográfico, alentado por el aumento de la demanda de mano de obra y el crecimiento de la actividad y la infraestructura turísticas. De 26.799 habitantes en 1970, pasó a albergar a 48.222 en 1980 y a 81.001 en 1991, convirtiéndose en la ciudad más poblada de la provincia de Río Negro desde $1980 .{ }^{1}$ Coincidentemente, el período de mayor inmigración desde Chile se corresponde con la dictadura de Augusto Pinochet. Junto al exilio político forzado por las persecuciones, los despidos masivos y las políticas de ajuste impulsados por la dictadura pinochetista alentaron la salida de miles de trabajadores. Se ha estimado entre 500.000 y 1.000 .000 el número de exiliados chilenos entre 1973-1989, tanto por causas políticas como por el deterioro de su situación económica (Yvette 2013). La principal región receptora fue la Patagonia argentina, y dentro de ella, Bariloche se ubica entre los destinos más destacados.

Ahora bien: ¿dónde se asentaron esos migrantes y cómo afrontaron la realidad con la que se encontraron? A diferencia de otras ciudades patagónicas como Neuquén, que registra una dilatada tradición de luchas sociales, ${ }^{2}$ en el caso de Bariloche ha predominado una migración interna de origen rural, donde las experiencias de organización y lucha social tienden a ser escasas o inexistentes (Benclowicz 2012a y 2012b). En ese marco, el aporte chileno va a resultar clave para la organización de distintas barriadas populares. ${ }^{3}$ El presente artículo aporta al estudio de los procesos de migración y conformación de los barrios populares de San Carlos de Bariloche atendiendo al papel que jugaron los migrantes internos y chilenos. Para eso, me centro en un caso emblemático: el de los primeros vecinos del asentamiento 10 de Diciembre, que tras protagonizar un importante proceso organizativo, lograron negociar colectivamente con el poder político municipal su traslado al barrio 28 de Abril, donde reside actualmente buena parte de ellos. ${ }^{4}$

El barrio 10 de Diciembre se desarrolla y crece como tal durante los años 70. A fines de esa década comienza la historia de organización barrial que se reconstruye en este trabajo, donde me propongo a su vez estudiar las representaciones que circularon y circulan entre los vecinos que participaron de ese proceso. En tanto componentes de diferentes visiones del mundo, las representaciones delinean los límites de lo que se considera que existe, que es justo, que es posible (Therborn, 1987). Teniendo esto en cuenta, se analizan entrevistas a informantes clave, boletines barriales y actas vecinales, atendiendo particularmente a los discursos de los vecinos acerca de sí mismos y sus acciones, y respecto del poder político con el que se enfrentan/negocian y al que reclaman/peticionan. ${ }^{5}$

El artículo está organizado del siguiente modo: en el primer apartado se contextualiza la historia del asentamiento considerando el desarrollo de las barriadas populares en general; en el segundo se aborda la primera etapa de organización barrial, momento en que se conforma la Junta Vecinal; en el tercero se examinan los rasgos de la acción barrial en el contexto de la negociación por el traslado colectivo de los vecinos al barrio 28 de Abril. En el último apartado se exponen las reflexiones finales.

\section{El barrio 10 de Diciembre en el contexto del crecimiento urbano}

La valorización inmobiliaria asociada al turismo y al crecimiento de la ciudad en general, junto a un patrón de larga data de concentración de la tierra urbana, ${ }^{6}$ generaron severas dificultades para el acceso a la propiedad de aquellos pobladores sin recursos materiales que migraron ante la posibilidad de acceder a un empleo asalariado (Benclowicz 2012b). En ese contexto, la política de hecho de las administraciones municipales y provinciales parece haber sido la de tolerar en general las ocupaciones de tierras en sectores marginales, principalmente al sur y al este del ejido, que se tornaban conflictivas cuando la propia expansión de la ciudad determinaba la pérdida de su carácter marginal. Ya para mediados de la década de 1960 se observó la existencia de un conjunto de viviendas precarias, sin servicios cloacales ni agua, relativamente dispersas en cotas de nivel elevadas (Hardoy 1964), al sur del casco céntrico original. Los datos indican que esta situación se amplió durante las siguientes décadas, desarrollándose un efecto de agregado de acciones individuales de familias asentadas en tierras vacantes (Cravino 2009). En este sentido, las acciones colectivas registradas en otras ciudades, que apuntan a legitimar las ocupaciones, han sido escasas, por lo que casi no existen casos de tomas de tierras como resultado de luchas sociales, como se puede observar en otras ciudades patagónicas, como Cipolletti o Neuquén. ${ }^{7}$

Para las décadas del 70 y 80 es posible hablar de un proceso de desarrollo de asentamientos, que se pueden definir por la carencia inicial de los habitantes de títulos de propiedad de los lotes, 
lo que en principio pueden diferenciarse de otras formas de hábitat popular como la de viviendas generadas mediante planes sociales, ajustadas a determinados estándares constructivos y legales, y de loteos privados de bajo costo en términos relativos y facilidades de financiación (Matossian 2009). Sin embargo, esta diferenciación puede resultar engañosa: existen casos, como el del barrio 28 de Abril, que como se verá, antes de empezar a constituirse como loteo social, es el resultado de un proceso que combina la organización colectiva y la amenaza del traslado forzoso desde un asentamiento que devino cercano al centro en función del crecimiento de la ciudad: el del barrio 10 de Diciembre. Por la cercanía del centro que finalmente terminó ostentando y por los niveles de hacinamiento, el 10 de Diciembre creció de manera asimilable a las villas de emergencia de Buenos Aires, también cercanas a los lugares de trabajo y hacinadas (Merklen 2005). El barrio 28 de Abril, que se desarrolló cumpliendo con los pasos legales previstos, asumió sin embargo características de precariedad propias de los asentamientos, ya que las viviendas terminan siendo entregadas sin terminar, al tiempo que se redoblan las presiones desde el Estado para que se efectúe el traslado.

Por otra parte, en los barrios surgidos de planes sociales y de loteos de bajo costo, las dificultades para sostener el mantenimiento de las viviendas suelen conducir a situaciones de precariedad que tienden a aproximarse a la de los barrios que surgieron como asentamientos. Tal es el caso de barrios como el Eva Perón I, que surgió de un programa municipal de viviendas que coronó un proceso de traslados forzosos, y que se encuentra en un estado de franco deterioro (Caram 2009). Por último, barrios como El Progreso, que surgieron a partir de loteos privados, incluyen un porcentaje significativo de lotes ocupados en forma directa, lo que los asemeja a los asentamientos.

La política de los sucesivos gobiernos municipales, en principio permisiva en cuanto a la existencia de los asentamientos, fue virando a medida que los límites del casco céntrico se extendían al calor del crecimiento económico de la ciudad. El viraje comenzó a manifestarse con claridad hacia fines de los años 70. A medida que el precio de mercado de los lotes aumentaba, la intendencia impuesta por la dictadura militar impulsó distintas iniciativas de "erradicación" y "relocalización" de asentamientos ubicados en áreas que se valorizaban económicamente. ${ }^{8}$ Por ese entonces, el asentamiento que más adelante fuera bautizado " 10 de Diciembre" por los propios vecinos, perdía paulatinamente su carácter periférico y se convertía en un territorio afectado por las políticas públicas asociadas a la especulación inmobiliaria.

El barrio 10 de Diciembre está ubicado en dos manzanas entre las calles 25 de Mayo, Emilio Frey, John O'Connor y Anasagasti, enfrente a un supermercado de cadena "La Anónima", que hacia la década de 1970 pertenecía a la firma "Lausen". La conformación del asentamiento data de los años 60 , en el contexto del proceso migratorio al que se hizo referencia más arriba. Para 1970 los registros indican una ocupación más densa (Abalerón 1993). Las tierras en cuestión pertenecían al Banco Hipotecario Nacional, y fueron compradas junto a dos hectáreas contiguas por la Municipalidad de San Carlos de Bariloche en 1981. El propósito era construir el Centro Administrativo municipal, como lo indica la ordenanza 167-I-83 de 1983. ${ }^{9}$ Sin embargo, ese proyecto nunca fue ejecutado. En cambio, el mismo año el municipio cedió gratuitamente parte de los lotes al estado provincial, para la construcción de viviendas por medio del Instituto de Planificación y Promoción de la Vivienda de Río Negro (IPPV), en una curiosa triangulación que implicó una transferencia de recursos invertida, en la que la administración municipal entregó a los estados nacional y provincial parte de su acotado patrimonio. El IPPV construyó 30 de las 70 viviendas que debía edificar, ${ }^{10}$ a las que no tuvieron acceso los vecinos del asentamiento.

El momento en que el municipio compró los terrenos al Banco Hipotecario Nacional coincide con los primeros registros de organización colectiva a nivel barrial, tema central de este trabajo. Durante toda la década de 1980 se desarrolló un proceso organizativo que dio lugar a una victoria o derrota parcial para los vecinos, según como se mire. Los pobladores originales del 10 de Diciembre no lograron permanecer en sus terrenos. Negociaron en cambio un traslado colectivo, en función de ello obtuvieron títulos de propiedad y un plan de viviendas en un barrio alejado del centro, el 28 de Abril, aunque la mayor parte de los compromisos asumidos por el estado municipal relacionados con la infraestructura de las viviendas y del nuevo barrio fueron incumplidos.

El traslado fue concretado entre fines de los años 80 y principios de los 90 , en un contexto de desborde urbano en el que las autoridades fueron 
forzadas a implementar medidas adicionales para ensayar respuestas a las necesidades y demandas de tierras y viviendas. Para esa época fueron adquiridas 34 hectáreas al sudoeste del casco céntrico destinadas al desarrollo de planes de vivienda, a partir de esto se construyeron los actuales barrios Unión y 2 de Abril. ${ }^{11}$ Con todo, el barrio 10 de Diciembre fue rápidamente repoblado por otros migrantes sin recursos materiales, evidenciando así la incapacidad del poder político para solucionar un agudo cuadro de crisis habitacional que persiste hasta nuestros días. Los nuevos vecinos del asentamiento protagonizaron a su vez otro proceso organizativo que derivó, hacia 2003, en un proyecto de regularización dominial. Pero esa es otra historia. Volvamos pues, a los primeros pobladores del 10 de Diciembre.

\section{Acciones y representaciones de la organización barrial}

Desde sus inicios, el barrio que más adelante quedaría conformado e identificado con el nombre " 10 de Diciembre" se nutrió notablemente de pobladores de origen chileno. Como ya se apuntó, esta corriente migratoria, que figura entre las principales de la localidad y puede remontarse a los orígenes de San Carlos de Bariloche, cobró un renovado impulso en el contexto del golpe de Estado liderado por Augusto Pinochet en 1973. Para la misma época existen testimonios acerca de la llegada al barrio de migrantes de zonas rurales del interior de la provincia de Río Negro, de paraguayos y de bolivianos. Esta población trabajadora, que no contaba con la posibilidad de acceder a la compra de un lote donde asentarse, se ubicaba generalmente en los márgenes de la ciudad, donde la permisividad de las autoridades se alternaba con las amenazas de desalojo.

La última dictadura militar argentina en particular es recordada por distintos vecinos como un período de hostigamiento cotidiano e iniciativas de desalojo que no se llegaron a concretar. La familia de L., ${ }^{12}$ por ejemplo, llegó a Bariloche desde el interior de la provincia de Río Negro y se instaló en el 10 de Diciembre. L. fue testigo durante su infancia y adolescencia del crecimiento económico de la propia ciudad, que hacia la segunda mitad de la década de 1970 ejercía notables presiones sobre el asentamiento:

En 1979, estaba en la intendencia de Bariloche el señor Barbieri y bueno, él sí casi nos pasa las topadoras, él sí casi nos pasa las topadoras. [...] y empezamos entonces nosotros ya en el 80, 81 a armar la Junta Vecinal que la logramos concretar en el 83, antes de la democracia logramos concretar la Junta Vecinal. Previamente a esto, tuvimos una reunión con el señor Barbieri, donde le pedimos una audiencia porque era mucho el hostigamiento que estábamos sufriendo, más los chicos, eh... nos armaron hospitales militares, la gente que salía a trabajar en la mañana para ellos éramos todos ladrones, salíamos a trabajar y llegábamos hasta la esquina... con documentación, nos demoraban... El gobierno autoritario, prepotente, como fueron los gobiernos de facto en nuestro país, así que bueno, nosotros luchamos... ${ }^{13}$

En este ejemplo, coincidente con otros testimonios, se visualiza una clara orientación por parte del gobierno de facto, caracterizada por el amedrentamiento sistemático a los vecinos del barrio, que vivían bajo la constante amenaza de desalojo. Pero aquí, la percepción del trato denigrante, de las violencias cotidianas, del tratamiento de los vecinos del barrio como delincuentes -hechos ampliamente documentados en numerosos asentamientos populares en distintos lugares del país- aparece acompañado de una respuesta que puede describirse como contenciosa: la orientación de la intendencia militar es cuestionada, discutida, resistida. Justamente "nosotros luchamos" marca una perspectiva de resistencia que está presente junto a otras representaciones que circulan actualmente entre los vecinos. En este caso, la Junta nace entonces de esa "lucha", lo que va a definir toda una línea de intervención y de percepción de la acción barrial.

Bien diferente es el conjunto de representaciones de la época de la dictadura que se desprenden de la entrevista a otro de los vecinos que participó después del restablecimiento de la democracia en las primeras comisiones vecinales:
P: ¿Qué recuerdo tiene de esa época?
R: Yo, eh...
P: No se podía hacer reuniones, eso estaba...
$\mathrm{R}$ : Claro, eso por un lado. Junta en la calle no había. No como ahora... ahora ves junta en todos lados. Pero... yo con los milicos... qué se yo... no digo que soy 
partidario de los milicos pero tampoco nunca me molestaron porque nunca fui un tipo así... de chico no fui maldadoso nunca. Pienso que no porque nunca hice maldad. Así que... jamás me molestaron. Así que... no sé qué puedo decir.

$\mathrm{P}:$ ¿Y había otra gente que sí molestaba?

R: No sé...

P: Nunca vio

R: Claro, eso tampoco, qué se yo...

P: Pero sí notó la diferencia entre un antes y un después de esa época del 83

R: Sí... diferencia no sé... sí, puede ser. ¿Qué diferencia puede ser que me....? ${ }^{14}$

El contraste entre esta representación del accionar de la dictadura resulta llamativo porque ambos entrevistados vivieron en el mismo lugar, bajo condiciones materiales similares y participaron del proceso de organización barrial. B. también nació en el interior de la provincia de Río Negro, en las afueras de un pueblo. Empezó a trabajar desde niño y a los 19 llegó a Bariloche para probar suerte. Un familiar los albergó en su casa del barrio 10 de Diciembre y más tarde logró construir allí su propia vivienda. Su caso es, en líneas generales, típico dentro de los migrantes sin recursos del interior de la provincia; no se diferencia demasiado del de $\mathrm{L}$.

Fuera de eso, en el relato de B. el hostigamiento militar oscila entre lo inexistente y lo justificado, en la medida en que se aplica a sujetos "maldadosos". Teniendo en cuenta el amplio consenso que existe en Argentina en torno a la condena del accionar de la dictadura, no deja de llamar la atención una representación de estas características propuesta por un poblador que sin duda experimentó esa violencia cotidiana. El ejemplo nos sugiere, por un lado, otro tipo de representación acerca de la vida cotidiana de los sectores populares bajo la dictadura, que no favorece la acción colectiva; a su vez, el hecho nos habla de la heterogeneidad de trayectorias presentes. Más allá de la aparente homogeneidad cultural, fueron migrantes con visiones del mundo diversas los que confluyeron en el colectivo que se organizó en torno al pedido/reclamo de tierra, vivienda y servicios. Entre el amplio margen que dejan los dos ejemplos examinados, se pueden ubicar el conjunto de representaciones respecto del accionar propio y el del poder político, más allá de la dictadura militar.
Para L., entre otros, fue necesaria la lucha aún en el contexto de la dictadura, de ese modo obtuvieron una mínima satisfacción de sus necesidades. B., en cambio, recuerda que:
"Alumbrado no había, eso lo tuvimos que... nos cobraron una cota no sé qué, había que pagarla, qué se yo... la cooperativa se encargó de cobrarlo, no sé cómo fue el tema... yo no entiendo mucho de eso pero para que pongan la luz tuvimos que hacer reuniones acá también". ${ }^{15}$

Siguiendo con el contrapunto, en este caso se evidencia un recuerdo-percepción muy difuso del proceso, en donde se realizaron un conjunto de acciones cuyo sentido no termina de aclararse y que se piensan como un deber-hacer. "Tuvimos que hacer reuniones" (para obtener la luz) indica una representación alternativa a la de la lucha, en donde el mero hecho de reunirse es condición suficiente para la satisfacción de las demandas. El hecho de que prácticamente no existan registros de acciones de protesta relevantes, ni antes ni después del restablecimiento de la democracia, robustece la representación de $\mathrm{B}$.

Lo cierto es que el crecimiento poblacional propio del período acrecentó las necesidades de contar con una mínima infraestructura. En efecto, el barrio no contaba con los servicios para garantizar las necesidades básicas. Para principios de la década de 1980 los vecinos contaban con una única canilla para obtener agua para todas las familias, no disponían de luz eléctrica ni de cloacas. Así, el amedrentamiento sistemático y la preocupación ante la posibilidad de ser desalojados, sumadas a las necesidades de infraestructura figuraron entre las principales motivaciones de la organización barrial, que se evidenció durante los últimos años de la dictadura.

cayó el gobierno militar y se armó la Junta, antes ya estábamos medio formados pasa que dos por tres teníamos a los milicos en la puerta de la casa [...] O., un chileno que se fue a Chile... y bueno ellos ya tenían experiencia de lo que era una Junta Vecinal en Chile; nosotros, U., O., G. y bueno, ellos nos dieron una mano para formar la primer Junta Vecinal [...] y así logramos conseguir el agua porque anteriormente se 
iba a buscar el agua a una canilla barrial que había, se traía en baldes, no había luz y juntándonos así entre varios vecinos pudimos poner un pilar comunitario que teníamos para una casa, para otra casa así que cruzábamos la cuadra entera con un solo pilar ${ }^{16}$

En este caso, la organización de los vecinos aparece como un elemento central a la hora de pensar los logros. E. nació en un paraje ubicado a unos $100 \mathrm{~km}$ de Bariloche, pasó su infancia en el campo con sus abuelos y después de casarse se vino a vivir a Bariloche. Para fines de los años 70 se asentó con su familia en lo que más tarde sería el barrio 10 de Diciembre. Igual que otros entrevistados, destaca el papel que jugaron los vecinos chilenos, los más numerosos en el asentamiento, en el proceso de organización barrial, y percibe en la línea de L., como intimidación la acción de "los milicos en la puerta de casa". Evidentemente, el asentamiento contaba con un conjunto de vecinos activos que impulsó una organización barrial en condiciones adversas.

G. nació en las afueras de Bariloche. Su familia se instaló en la ciudad cuando era un niño. Al poco tiempo su madre se quedó sola con 11 hijos y decidió instalarse en un descampado donde se distinguían un puñado de casillas precarias, que más adelante sería identificado como el barrio 10 de Diciembre. Allí, los inmigrantes chilenos se destacaban numéricamente-algunos entrevistados hablan de hasta 70 por ciento de vecinos de ese origen- y una parte de ellos, entre los que figuran exiliados con trayectorias de militancia, jugó un papel central en el proceso de organización barrial:

Nosotros prácticamente no sabíamos nada de política, no sabíamos nada de nada ¿viste? [...] Ahora recién están... pero nosotros de lucha, así, no sabíamos nada. Yo te cuento que U., ellos venían de la lucha de la universidad, ellos sabían cómo... viste que hizo un boletín. Eso es porque la gente sabía cómo era, pero nosotros éramos cero a la izquierda total. Nosotros vivíamos, laburábamos, y dormíamos y hasta ahora que vos ves que yo... o sea que nosotros no vivíamos, no sabíamos nada cómo era... lo que era una ordenanza, lo que era una personalidad jurídica, lo que era una reunión, una asamblea, lo que era un libro de acta, no sabíamos eso ¡nada! [...] Y acá la gente chilena era toda de cada partido ¿viste? casi más eran los de izquierda que venían acá. [...] Los locos sabían lo que era una comisión, sabían lo que era un barrio. Ellos están mucho más adelantados que nosotros los argentinos, en ese sentido, mucho más. ${ }^{17}$

Así pues, la lucha por la construcción de un lugar tanto material como simbólicamente aparece vehiculizada por actores empapados en la tradición de izquierdas chilena que cuentan con un capital militante (Poupeau 2007), ausente entre la mayor parte de los argentinos que residían en el barrio. Es posible pensar que este saber-hacer permitió la canalización de expectativas variadas y de actores ideológicamente heterogéneos en torno a un proceso que fue formulando sucesivos reclamos y obteniendo parte de ellos durante los primeros años de la presidencia de Raúl Alfonsín, entre los que se destacan la instalación de nuevas canillas públicas de agua y la luz eléctrica domiciliaria. Más allá de esos reclamos, la Junta Vecinal se convirtió en una verdadera usina de actividades sociales y deportivas, que contribuyeron a fortalecer la identificación de los vecinos con el barrio. Entre las principales actividades y proyectos, los vecinos del $10 \mathrm{de}$ Diciembre organizaron un club de fútbol, talleres y obras de teatro y un boletín de confección artesanal con información relativa a eventos, reclamos y gestiones que se llevaban adelante.

Estas actividades potenciaron una demanda que terminó siendo central: la adquisición de los lotes y la posibilidad de ser incluidos en un plan de construcción de viviendas. Las amenazas de desalojo, que se reactivaban en el contexto del alza del valor de la propiedad urbana, encontró a los vecinos organizados y reclamando soluciones. Así, hacia mediados de los años 80 se inició una larga negociación entre el gobierno municipal y los vecinos, que derivó en el traslado de la mayor parte de ellos al barrio 28 de Abril, ubicado por entonces en las afueras de la ciudad, al sur del casco céntrico. El siguiente apartado indaga en torno a ese proceso.

\section{¿Reclamar o pedir? Hacia el traslado}

En agosto de 1986 el invierno hace sentir su rigor en Bariloche, en particular en asentamientos 
como el 10 de Diciembre, caracterizados por reunir un conjunto de viviendas sumamente precarias, nada aptas para el clima de la zona. Para el 23 los vecinos del barrio organizan una Asamblea, la primera que queda asentada en el libro de Actas de la Junta Vecinal, que ha logrado ser reconocida como interlocutor válido del gobierno municipal de la Unión Cívica Radical (UCR). Concurren 108 vecinos en representación de las aproximadamente 140 familias que residen por ese entonces en el barrio. La Asamblea, que se hace en una escuela ubicada en las cercanías del barrio, cuenta con la presencia de funcionarios municipales y concejales. El tema central de la convocatoria: la propuesta de reubicación formulada por el municipio, que pretende satisfacer las presiones inmobiliarias en un contexto caracterizado por la organización de los vecinos.

La propuesta consiste en la venta de lotes y construcción de viviendas en un plazo de dos años, que serán adquiridos con facilidades por los vecinos. Se trata del actual barrio 28 de Abril, emplazado en las afueras de la ciudad en una zona por entonces denominada "Quinta 58"; se trata de tierras altas ubicadas a 4 kilómetros al sur del centro. A partir de los reclamos de los vecinos, las autoridades se comprometen a instrumentar formas de pago acordes a los ingresos y la escrituración sin cargo. A su vez, el gobierno garantiza que el nuevo espacio contará con servicios, centro asistencial, áreas verdes, mobiliario para viviendas. Adicionalmente, los funcionarios se comprometen a atender los problemas sociales más urgentes antes del traslado, a agilizar trámites, a apoyar con recursos y servicios a la construcción de viviendas, y a contratar a vecinos del barrio. ${ }^{18}$

Los planteos y la masividad se sostienen en el tiempo. Un mes después se celebra otra Asamblea a la que asisten 123 personas, en la que se demanda al gobierno municipal que el nuevo barrio tenga capacidad para albergar a la totalidad de los vecinos. ${ }^{19}$ Aun así, como se mencionó, no existen registros de acciones de lucha de envergadura protagonizadas por los habitantes del 10 de Diciembre. Parecería que la sola organización, en el contexto del restablecimiento de una democracia pensada desde el gobierno nacional como capaz de alimentar, educar y atender las necesidades sanitarias de la población, ${ }^{20}$ resultó suficiente para visibilizar la problemática y forzar a un gobierno municipal con proyectos inmobiliarios en la zona a plantear soluciones que contemplen los intereses de la población en cuestión.
Poco después empieza a editarse un boletín barrial, herramienta que juega un importante papel en la visibilización del proceso de negociación con los funcionarios tanto hacia afuera como hacia dentro del barrio. Como se mencionó, el boletín ofrecía información acerca de eventos, reclamos y gestiones que se llevaban adelante, y era editado por los vecinos. Aun así, su financiamiento dependía en ocasiones de la propia municipalidad, y entre sus páginas se reservaba un amplio espacio para asistentes sociales y funcionarios. Los discursos del boletín aportan datos interesantes para el análisis de las representaciones que circulaban entre los vecinos a propósito de las demandas y del proceso de traslado.

Uno de los aspectos que llama la atención, teniendo en cuenta el carácter masivo de las Asambleas, es el permanente reclamo dirigido a los vecinos para incrementar su participación. Más allá de las reuniones, los boletines y las actas dan cuenta de la organización de rifas y eventos sociales -chocolate por el día del niño, locro comunitario para celebrar en 25 de Mayo, funciones de títeres para niños, centro de alfabetización, etc.- A pesar de eso, desde el boletín se sugiere la falta de compromiso por parte de los vecinos. Así, por ejemplo, se señala que:

\begin{abstract}
Aclaramos que Junta Vecinal, es un grupo de vecinos que viven en un barrio y se han organizado para concretar objetivos comunes (en nuestro caso 'viviendas dignas'). Sí señor. Sí señora. Frente a alguna colaboración que usted necesite de la Junta Vecinal, pídala a su vecino. Ese vecino es miembro de la Junta Vecinal con sus mismos derechos y obligaciones y es allí donde se verá el real sentido solidario. No debe ser el presidente o el secretario quienes hagan todo. ${ }^{21}$
\end{abstract}

Este y otros fragmentos sugieren la presencia de un grupo de vecinos activos que jugaron un papel dirigente, y un amplio sector que posiblemente no distinguía a los anteriores de los funcionarios municipales. En este sentido, se percibe la existencia de un abismo cultural que no todos estaban en condiciones -o dispuestos- de salvar. Por momentos, los métodos de los dirigentes barriales se confunden con los de los funcionarios municipales, especialmente en lo que hace a formalidades y procedimientos. A esto se le suma que posiblemente por una cuestión táctica, 
el municipio suele aparecer en las líneas del boletín como un gobierno atento y dispuesto a atender necesidades de la gente, por lo que no es fácil distinguir una organización barrial independiente del poder. Así, después de una implementación marcadamente deficiente del llamado "Plan Calor", un programa de asistencia y abastecimiento municipal de leña para calefaccionar las viviendas en el período invernal, desde el boletín se señala:

\begin{abstract}
A pesar de haber hecho un llamado a los vecinos a participar de las actividades de esta Junta Vecinal y del propio Boletín, esto no ha ocurrido como hubiéramos deseado, salvo algunas excepciones. Por ejemplo, con la implementación del "Plan Calor", aparte de los comentarios a favor, las críticas en contra no fueron canalizadas como corresponde [...] todo vecino que desee cuestionar las actividades de la Comisión Directiva, plantear sus inquietudes o señalar actividades de trabajo, puede hacerlo por nota escrita a la Comisión. Incluso, agregamos, pidiendo participar personalmente en sus reuniones, dirigiéndose por intermedio de algún miembro de la comisión. ${ }^{22}$
\end{abstract}

El mecanismo que se prevé en primer término para expresar el disenso -la nota escrita- se asemeja a un procedimiento burocrático estatal. De hecho, quien envía notas escritas que son publicadas en el boletín es el propio gobierno municipal.

Otro aspecto a considerar es la modificación de las posibilidades de intervención de los activistas barriales más experimentados, de origen chileno. Desde el punto de vista legal, su participación en las Juntas Vecinales estaba garantizada desde 1958 por una resolución de la Presidencia del Consejo Municipal, que establecía el derecho de participación de todos los vecinos sin distinción de nacionalidad. ${ }^{23}$ No obstante, en 1986, pocos años después de restablecida la democracia, se promulgó una nueva norma que alteró significativamente las condiciones de participación, en particular en los cargos directivos de las Juntas: a partir de ese momento "Los extranjeros con radicación definitiva en el país podrán ser elegidos, pero en ningún caso excederán de la tercera parte del total de los miembros que componen el cuerpo". ${ }^{24}$

Así, a pocos años de andar, la democracia restablecida limitó, de derecho y de hecho, las posibilidades de participación a nivel vecinal. En ese contexto, para fines de 1987 asume una nueva directiva en la Junta Vecinal y se procura a partir de ese momento el alineamiento con las autoridades, abandonando el perfil contencioso propio del reclamo y de la acción colectiva. Esto no parece haber implicado una disminución en lo que hace al nivel de visibilidad logrado por la organización barrial. A principios de 1988 el gobernador Horacio Massaccesi, de visita en Bariloche, concurrió al asentamiento 10 de Diciembre acompañado entre otros por el intendente de la ciudad, lo que habla de un espacio conquistado en la agenda local por parte de los vecinos. En esa oportunidad, el boletín apunta que:

\section{Después de escuchar diversas peticiones, el Gr. Massaccesi, dio respuestas positivas, que levantaron la fe y la esperanza que hemos depositado en nuestras autoridades, legalmente elegidas. En esta visita llegó acompañado por el Sr. intendente Cdor. Edgardo Gagliardi [...] y otras autoridades que pedimos perdón por no acordarnos de sus nombres y cargos que desempeñan en nuestro beneficio [...] Con anterioridad se comprometió a donar una máquina de escribir y a cooperar en la edición de este boletín. ${ }^{25}$}

El indisimulado alineamiento con el gobierno radical y el predominio del pedido del reclamo no parece dar lugar a grandes contraprestaciones, al menos en lo inmediato. Tras la presencia del máximo mandatario provincial en el barrio, y en un contexto de postergaciones sociales extremas, se exhibe entre los principales logros la promesa de donación de una máquina de escribir y de financiamiento del propio boletín, hecho que favorece que se consolide como un órgano de propaganda del gobierno. Mientras tanto, las viviendas comprometidas siguen siendo demoradas. Esto último todavía se vio dificultado para los inmigrantes chilenos por la vigencia de la Ley de Fronteras, ${ }^{26}$ que alcanza a esta ciudad, y que da lugar a ciertas trabas burocráticas y legales que muchas veces terminan bloqueando la posibilidad de acceder a la propiedad. Así, por ejemplo, en el Libro de Actas del barrio 10 de Diciembre consta detalladamente la política de las autoridades: "Al grupo familiar extranjero con hijo argentino, se verá la forma legal de entregar en propiedad el lote solo a la mayoría de edad de este, mientras esto 
no sea superado el jefe de familia tendrá tenencia precaria". ${ }^{27}$

De este modo, cuando después de largas dilaciones el traslado se concretó -en distintas etapas entre 1989 y 1992, bajo las intendencias de Eduardo Gagliardi (UCR) y de María del Rosario Severino de Costa, del Partido Justicialista (PJ)-, la discriminación de los chilenos constituyó un elemento de división adicional entre los vecinos originalmente movilizados. En el ínterin se registró una reactivación de la acción colectiva, que incluyó la elaboración de un petitorio y una movilización al Centro Cívico, la plaza central de la ciudad y sede de la Intendencia, la acción de protesta más importante que aparece en los registros relevados. ${ }^{28}$ $Y$ es que el perfil contencioso, ya experimentado en distinta medida por los vecinos, ha dejado su huella.

\section{Palabras finales}

A lo largo de este trabajo examiné el proceso de organización de los vecinos del asentamiento 10 de Diciembre desde fines de la década de 1970 hasta el traslado al barrio 28 de abril, a principios de los años 90. La relevancia del caso reside particularmente en el hecho de que permite ilustrar un conjunto de rasgos que caracterizan a una ciudad como Bariloche, donde la expansión de la actividad turística oculta su contraparte, la afluencia masiva de migrantes sin recursos materiales, cuyas experiencias son escasamente conocidas.

Con relación también al desarrollo de esa acción, procuré identificar diferentes representaciones que circulan y circularon entre los protagonistas, sobre sí mismos y sobre el poder político. Sugerí que en ciertos casos se evidencia una tendencia a naturalizar la subordinación de los primeros respecto del segundo. Es posible pensar que cuando esta tendencia prevalece, la petición agota el horizonte de acciones posibles. En otros casos, aparece el reconocimiento-descubrimiento de varios derechos sociales. Este segundo conjunto habilita, en cierto modo, el pensamiento crítico respecto de las condiciones de vida imperantes y la posterior acción colectiva de carácter contencioso que involucra el reclamo. En este sentido, la participación de migrantes de origen chileno empapados en la tradición de izquierdas parece haber sido relevante. Portadores de un saber-hacer en torno a la organización colectiva, motorizaron los reclamos de un conjunto heterogéneo de vecinos, que en muchos casos no visualizaban las condiciones de subordinación y violencia a las que se encontraban sometidos como tales.

En este tipo de recorridos, una parte de los migrantes sin recursos materiales adquiere los recursos simbólicos necesarios para obtener los anteriores. En otras palabras, la visualización de las relaciones de opresión por parte de los sujetos constituye un paso fundamental en la puesta en marcha de procesos de lucha. En este sentido, la historia de los primeros vecinos del 10 de Diciembre se configura como un caso paradigmático de la lucha por la vivienda, problema que continúa ocupando un lugar central en el Bariloche del siglo XXI.

\section{Agradecimientos}

Agradezco especialmente a Solange Achon y Mariel Wörner por su entusiasta colaboración en el trabajo de campo, y a los vecinos que gentilmente nos abrieron las puertas de sus casas y sus experiencias.

\section{Referencias Citadas}

Abalerón, C.

1993 Las transformaciones del espacio rural en el área periurbana: el caso de la periurbanización marginal de San Carlos de Bariloche. Informe. Fundación Bariloche.

Aceves Lozano, J.

2000 Las fuentes de la memoria. Problemas metodológicos. Voces Recobradas 7: 6-10.

Adleson, L., Camarena, M e Iparraguirre, H.

2000 Historia social y testimonios orales. Cuicuilco 22: 68-74.

Aiziczon, Fernando

2006 Neuquén como campo de protesta. Sujetos Sociales y Conflicto en la Norpatagonia Argentina, editado por

O. Favaro. http://biblioteca.clacso.edu.ar/Argentina/ cehepyc-uncoma/20110418035513/cap8.pdf. La Colmena, Buenos Aires.

Barelli, A. I.

2014 La Virgen del Carmen en San Carlos de Bariloche: devoción, pertenencia chilena y construcción identitaria (1970-1994). Revista de Historia Americana y Argentina 49: 1-32.

Benclowicz, J.

2012a Migración chilena, pueblos originarios y discursos sobre Bariloche: reflexiones en torno a las representaciones hegemónicas en la historia reciente. Estudios Trasandinos 17: 41-58 Benclowicz, J.

2012b Migraciones y representaciones populares en una ciudad turística. Notas sobre San Carlos de Bariloche. Diálogo Andino 40, 83-96. 
Betaux, D.

1989 Los relatos de vida en el análisis social. Historia y fuente Oral 1: 87-96.

Bourdieu, P. 2008 El sentido práctico. Siglo XXI, Buenos Aires.

Caram, M.

2009 Buscando respuestas a la informalidad en el acceso al suelo: los presupuestos participativos como herramienta de cogestión urbana municipal. Tesis de Maestría en Hábitat y vivienda, Facultad de Arquitectura, Urbanismo y Diseño, Universidad Nacional de Mar del Plata.

Caram, M. y Pérez, S.

2006 Enmarcando el problema del acceso a la tierra: acerca de las recientes ocupaciones de tierra urbana en San Carlos de Bariloche. Ponencia presentada en el Seminario Latinoamericano Teoría y Política sobre Asentamientos Informales, Buenos Aires, UNGS

Cravino, M. C.

2009 El nuevo horizonte de la informalidad en el Área Metropolitana de Buenos Aires. En Favela e Mercado Informal, editado por P. Abramo, pp. 272-302. Habitare/ FINEP, San Paulo.

Fuentes, R. y Núñez, P.

2007 Sectores Populares: Identidad Cultural e Historia en Bariloche, Núcleo Patagónico, Bariloche.

Fuentes, R. y Núñez P.

2008 Identidad y Lucha por la Tierra en San Carlos de Bariloche, Núcleo Patagónico Bariloche.

Giaretto, M.

2011 La ciudad en conflicto. Publifadecs, Roca.

Ginzburg, C.

1986 El queso y los gusanos. Muchnik, Barcelona.
Hardoy, J.

1964 Plan físico para San Carlos de Bariloche. Buenos Aires.

Kropff, L.

2002 Indios, chilotes y vecinos en una ciudad patagónica, en Cuadernos de Antropología Social 16, 211-229.

Kropff, L.

2005 Bariloche: ¿una Suiza argentina?, en Desde la Patagonia: difundiendo saberes 2, 32-37 CRUB-UNCo, Bariloche.

Levi, G.

1990 La herencia inmaterial. Narea, Barcelona.

Matossian, B.

2009 Migración chilena en barrios populares de San Carlos de Bariloche: el caso del Barrio Arrayanes". En Movilidad y Migraciones, editado por A. Guiance, 187-200. IMHCHCONICET, Buenos Aires.

Matossian, B.

2010 Expansión urbana y migración. El caso de los migrantes chilenos en San Carlos de Bariloche como actores destacados en la conformación de barrios populares, en Scripta Nova XIV, 331 http://www.ub.edu/geocrit/sn/sn-331/sn-331-76. htm.

Merklen, D.

2005 Pobres Ciudadanos. Las Clases Populares en la Era Democrática (Argentina, 1983-2003). Gorla, Buenos Aires.

Poupeau, F.

2007 Dominación y Movilizaciones, Ferreyra Editor, Córdoba.

Therborn, G. 1987. La Ideología del Poder y el Poder de la Ideología, Siglo XXI, Buenos Aires.

Yvette, M. G.

2013 El trabajo militante del exilio chileno en Francia: Contextualización, descripción, micromedios de comunicación y sus impactos. Revista Izquierdas 17, 81-92.

\section{Notas}

1 Las cifras corresponden a los Censos Nacionales de Población de 1970, 1980 y 2010.

2 Acerca de este punto puede verse Aiziczon (2006).

3 En este punto, además de los estudios clásicos de Bourdieu (2008) respecto de la noción de habitus y la predisposición a la acción, resultan particularmente relevantes los aportes de Poupeau (2007) con relación al capital militante puesto en juego por los activistas, que habilita cauces para la acción social en distintos contextos.

4 En cuanto al foco en un caso específico se puede reconocer la influencia de la Antropología, y por su intermedio de los trabajos microhistóricos que plantearon -a partir de la década de 1970- la reducción de la escala de análisis predominante hasta ese momento en la historiografía sin prescindir del contexto general. Véase entre otros Ginzburg (1986) y Levi (1990).

5 La utilización de fuentes orales en particular permitió la aproximación a acontecimientos escasamente registrados en otros medios y contribuyó a la indagación acerca de distintos aspectos de las luchas, la vida cotidiana y la cultura de los sujetos que no resultan accesibles a partir de las fuentes escritas. Para evitar distorsiones en los resultados se tuvo presente que la entrevista es una construcción de a dos entre el investigador y el informante sometida a los mecanismos selectivos de la memoria. Por otra parte, las entrevistas han sido contrastadas entre sí, hasta alcanzar un grado de saturación en los casos que resultó pertinente, o bien han sido confrontadas con fuentes escritas, siempre teniendo en cuenta el marco histórico general. Pertinente al uso de fuentes orales y los recaudos del caso pueden verse, entre otros Aceves Lozano (1990), Adleson et al. (1990), Betaux (1989).

6 Una política común que implementaron todas las administraciones estatales en la ciudad, especialmente a partir de la creación del Parque Nacional Nahuel Huapi, fue la de habilitar el loteo de una enorme cantidad de hectáreas independientemente de la ocupación efectiva de las tierras. Así, hacia 1964, en 40 loteos realizados en décadas anteriores, se contabilizaban 4.202 lotes, de estos solo 286 estaban construidos, es decir, el 93,6 por ciento permanecían como terrenos baldíos (Hardoy 1964).

7 Del caso de Neuquén puede verse Giaretto (2011). Para un caso excepcional de tomas de tierras que pueden llegar a pensarse como acciones colectivas véase Caram y Pérez (2006).

$8 \quad$ Véase por ejemplo diario La Última. 1980. Continúa la erradicación de viviendas precarias. Bariloche, 5 de septiembre.

$9 \quad$ Municipalidad de S. C. de Bariloche, Ordenanza $\mathrm{N}^{\circ} 1586$ CM-06, 2006. 
Municipalidad de S. C. de Bariloche, Ordenanza No $1586-$ CM-06, 2006.

11 Lo que a su vez involucró un proceso organizativo de distintos barrios afectados para el traslado a las " 34 hectáreas". Un relato de uno de sus protagonistas se encuentra en Carfagnini, E. s/f. La tierra: una utopía convocante. http://www.logospoetry.org/document.php.

12 A fin de proteger la identidad de los vecinos entrevistados, se opta por identificarlos con iniciales falsas.

13 Entrevista de Solange Achon y Mariel Wörner a L., Bariloche, 27 de agosto de 2013.

14 Entrevista de Solange Achon y Mariel Wörner a B., Bariloche, 18 de septiembre de 2013.

15 Entrevista de Solange Achon y Mariel Wörner a B., Bariloche, 18 de septiembre de 2013.

16 Entrevista de Solange Achon y Mariel Wörner a E., Bariloche, 8 de octubre de 2013.

17 Entrevista de Solange Achon y Mariel Wörner a G., Bariloche, 23 de marzo de 2013.

18 Libro de Actas de la Junta Vecinal 10 de Diciembre, Acta del 23 de agosto de 1986. Hacia 2007 se inició en el barrio un plan de viviendas de la Fundación Madres de Plaza de Mayo que retomó, quizás sin saberlo, la modalidad de autoconstrucción planteado por los vecinos hace más de 20 años.

19 Libro de Actas de la Junta Vecinal 10 de Diciembre, Acta del 27 de septiembre de 1986.

20 Véase el famoso discurso de Raúl Alfonsín del 30 de octubre de 1983, después de ser proclamado Presidente electo.

21 Boletín de la Junta Vecinal 10 de Diciembre, nro 4, 15 de agosto de 1987, p. 2.

22 Boletín de la Junta Vecinal 10 de Diciembre, nro 3, 15 de agosto de 1987, p. 1.

23 Resolución N³7-C-58 de la Presidencia del Consejo Municipal de San Carlos de Bariloche, 1958.

24 Ordenanza N ${ }^{\circ}$ 194-CM-86 del Consejo Municipal de San Carlos de Bariloche, artículo $18^{\circ}, 1986$.

25 Boletín de la Junta Vecinal 10 de Diciembre, nro 9, 29 de febrero de 1988, p. 2. El destacado es mío.

26 Boletín Oficial de la República Argentina, 25 de abril de 1945. Decreto Ley 15385.

27 Libro de Actas de la Junta Vecinal 10 de Diciembre, Acta de 10 de Diciembre de 1986.

28 Libro de Actas de la Junta Vecinal 10 de Diciembre, Acta s/f (posterior al 13 de septiembre de 1991. La magnitud de la movilización no pudo ser corroborada). 
